\title{
Mirror-reversal of a face is perceived as expressing emotions more intensely
}

\author{
H.S. Asthana and M.K. Mandal \\ Department of Psychology, Banaras Hindu University, Varanasi - 221 005, India
}

Correspondence to: H.S. Asthana at above address

\begin{abstract}
This study examined hemispatial bias in a free-viewing condition of the judgement of facial expressions of emotions. Righthanded male subjects were asked to judge the intensity, in terms of expressiveness, of facial emotion in normal and mirror-reversed orientations. Expressions in mirror-reversed orientation were perceived as more intense than in normal orientation.
\end{abstract}

Keywords: Face processing - Handedness - Emotional expression - Asymmetry

\section{INTRODUCTION}

Neuropsychological research has shown that the left side of the face is more pronounced (as a function of the right hemisphere) during expressions of emotions in general (Sackeim et al., 1978; Borod, 1990; Asthana and Mandal, 1996). Researchers in this field have also indicated that the perceiver's left hemiface falling on the side of expressor's hemiface (i.e. right) determines judgement about the structural functional resemblance with a whole face (Gilbert and Bakan, 1973; Moreno et al., 1990; see also Christian and Hackworth, 1993). This is because the right hemisphere with its contralateral fibre projections to the left-visual-field largely mediates face processing (Borod et al., 1990). Both speculations have ample empirical support, and it is possible that the hemifacial and hemispatial bias interact during faceto-face communication (Mandal and Singh, 1990). In such cases, the side of the face that is more pronounced during emotion expression is not the side the observer normally notices (Campbell, 1986; Sackeim et al., 1978).

We believe therefore that the mirror-reversal of a facial expression (left-right) would be perceived as more intense in comparison to its normal orientation (right-left) because in such cases, the hemiface (left) dominant for emotion expression would be processed by the side of the hemisphere (left) that determines judgement about a whole face in a free-viewing condition. The hypothesis was tested in a simple experiment with certain methodological variations from the earlier studies in which similarity judgement between test-target photographs (Gilbert and Bakan, 1973) or rating judgement for asymmetry of an expression (Borod et al., 1990) were the dependent measures. In this study, subjects were asked to compare the normal and mirror-reversal orientation of a facial emotion in terms of its intensity of expression. To avoid the scanning bias accrued out of reading habit (left to right), the photographs were presented in upper and lower regions of the central - visual field.

\section{METHOD}

Forty right-handed male subjects (mean age 24.5 years \pm 7.2 ; mean education $13.2 \pm 5.0$ ) participated in the experiment. Subjects with an impaired sighting performance, a history of brain-disorder, or a history of psychiatric illness were not included. Handedness in subjects was assessed by a Hand Preference Inventory (Mandal, et al. 1992a).

A total of 20 full face photographs depicting expressions of happiness (five males and five females) and sadness (five males and five females), were selected from a series of photographs developed by Mandal (1987). (Photographs are available from microfiche publications, Documents NAPS D4267, POB, 3513, Grand Central Station, New York, NY 10017, USA.) The photographs were all standardized, clearly recognizable (over 70\%), unblended with 
other emotions, and located on a scale of intensity of expression. The faces depicted in the photographs were all unfamiliar to the subjects. For each selected photograph, two prints, one in normal orientation (RL) and the other in mirror-reversed (LR) orientation, were taken. Photographs were presented through a slide projector with the order of presentations counter-balanced. Subjects were instructed to look at the two photographs of an expression (RL and LR) and prefer one (top or bottom) in a forcedchoice response format that displayed the intended emotion more intensely.

\section{RESULTS}

The frequency of preference for RL or LR of a facial emotion was the dependent measure (Table I).

TABLE I. Preferred judgements of expression for photographs presented in normal and mirror-reversed orientation

\begin{tabular}{lcc}
\hline $\begin{array}{l}\text { Direction of } \\
\text { preference }\end{array}$ & \multicolumn{2}{c}{$\begin{array}{c}\text { Number of preferred } \\
\text { emotions }\end{array}$} \\
\cline { 2 - 3 } & Happy & Sad \\
\hline $\begin{array}{l}\text { Mirror-reversed } \\
\text { orientation (LR) }\end{array}$ & $225(56.25 \%)$ & $233(58.25 \%)$ \\
Normal orientation (RL) & $175(43.75 \%)$ & $167(41.75 \%)$ \\
\hline
\end{tabular}

'Total judgements 400 (40 subjects, 10 photographs each).

A laterality ratio, calculated as preference for LR minus preference for RL divided by the total number of preferences (Bryden, 1982), was calculated for each subjects judgement. The mean laterality ratio was calculated as happy $=+0.14$, sad $=+0.17$, indicating a preferece for LR over RL. Photographs presented in LR orientation were judged as significantly more intense that those in $\mathrm{RL}, \mathrm{F}(1,78)=$ $20.17, p<0.01$. The main effect of emotion could not be tested in the factorial ANOVA of Emotion $\times$ Facial orientation because the total number of preferences was identical for both the emotions (happy, sad). The interaction of Emotion $\mathrm{x}$ Facial orientation was non-significant.

A separate analysis was done to identify the emotion effect in which expressions of LR orientation were found to have been judged more intense than $\mathrm{RL}$ orientation for happy $\left(\chi^{2}=6.25, \mathrm{df}=1, p<0.01\right)$ as well as sad $\left(\chi^{2}=10.88, \mathrm{df}=1, p<0.01\right)$ emotions.

\section{DISCUSSION}

There is ample evidence that the left of the face is more dominant that the right in expression of emotion (see Borod et al., 1990), and a perceiver's left-visual-field rather than right-visual-field is more dominant in judgement about a whole face (see Campbell, 1986).

The present findings indicate that the dominant facial side (left) presented to the dominant perceiver side (left) was judged as more intense than the dominant facial side presented to the non-dominant perceiver side (right) or conversely the non-dominant facial side to the dominant perceiver side. The findings corroborate the observations of Borod and her associates (Borod et al., 1990) in 'which expressions viewed in the reversed orientation were rated as more left sided than in the normal orientation'. Given such a finding, the question arises as to why the dominant side of an expressor's face is processed by the nondominant perceiver side of an observer during normal social interactions. Earlier speculations that 'the left of face is more private/emotional whereas the right is more public/communicative' (Wolff, 1933) have been supported by researchers at a later date (Sackeim et al., 1978; Mandall et al., 1992b) and the impact of lateralization of facial expression on the attribution of personality (Kowner, 1995) and facial attractiveness with its possible evolutionary basis (Zaidel et al., 1995) was evaluated. These findings give rise to two possibilities. First, we learn in the course of human development to civilize intense emotional expressions of subcortical origin by the side of the face (right) which is more under the voluntary motor control of the relatively less emotional side of the cerebral hemisphere (i.e. left) for the facility of social interaction. Second, we evolve a strategy in the course of civilization to process the emotionally pronounced side of the face (left) by the hemisphere side (left) that largely mediates cognitive ability, and is non-dominant for emotional processing (right-visual-field) with an ultimate aim to allow us to have a 'temporal priority of cognition over emotion' (Lazarus, 1984).

These assumptions are, however, purely speculative and need support from other empirical findings.

\section{Acknowledgements}

This research was supported in part by a CSIR research (contingency) grant (9/13(681)94, EMR-1) awarded to H.S. Asthana.

\section{REFERENCES}

Asthana HS and Mandal MK (1996) Hemi-regional variations in face during emotion expression. British Journal of Psychology, in press.

Borod JC and Koff E (1990) Lateralization for facial emotional behaviour: A methodological perspective. International Journal of Psychology, 25, 157-177. 
Borod JC, Clair J St, Koff E, and Alpert M (1990) Perceiver and poser asymmetries in processing facial emotion. Brain and Cognition, 13, 167

Campbell R (1986) Asymmetries of facial action: Some facts and fancies of normal face movement. In R. Bruyer (Ed.), The Neuropsychology of Facial Perception and Facial Expression (Ed. R Bruyer) pp. 247-267. Lawrence Erlbaum, Hillsdale, NJ.

Christman SD and Hackworth MD (1993) Equivalent perceptual asymmetries for free viewing of positive and negative emotional expressions in chimeric faces. Neuropsychologia, 31, 621-624

Gilbert C and Bakan P (1973) Visual asymmetry in perception of faces. Neuropsychologia, 11, 355-362

Kowner R (1995). Laterality in facial expressions and its effect on attribution of emotion and personality: A reconsideration. Neuropsychologia, 33, 539-560.

Lazarus RS (1984) On the primacy of cognition. American Psychologist, 39, 124-137.

Mandal MK (1987) Decoding of facial emotions, in terms of expressiveness by schizophrenics and depressives. Psychiatry, 50, 371-376.

Mandal MK and Singh SK (1990) Lateral asymmetry in identification and expression of facial emotions. Cognition and Emotion, 4, 61-70.
Mandal MK, Asthana HS, Pandey G and Singh SK (1992a) Hand preference in India. International Journal of Psychology, 27, 433-442.

Mandal MK, Asthana HS, Madan SK and Pandey R (1992b) Hemifacial display of emotion in the resting state. Behavioural Neurology, 5, 169-171.

Moreno C, Borod JC, Welkowitz J and Alpert M (1990) Lateralization for the expression and perception of facial emotion as a function of age. Neuropsychologia, 28, 199-209.

Sakeim HA, Gur RC and Saucy MC (1978) Emotions are expressed more strongly on the left side of the face. Science, 202, 434-435.

Wolff W (1993) The experimental study of forms of expression. Character and Personality, 2, 168-173

Zaidel DW, Chen AC and German C (1995) She is not a beauty even when she smiles. Possible evolutionary basis for a relationship between facial attractiveness and hemispheric specialization. Neuropsychologia, 5, 649-658.

(Received 11 March 1996; accepted 10 October 1996) 


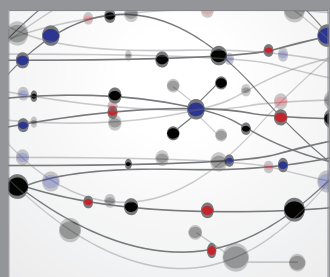

The Scientific World Journal
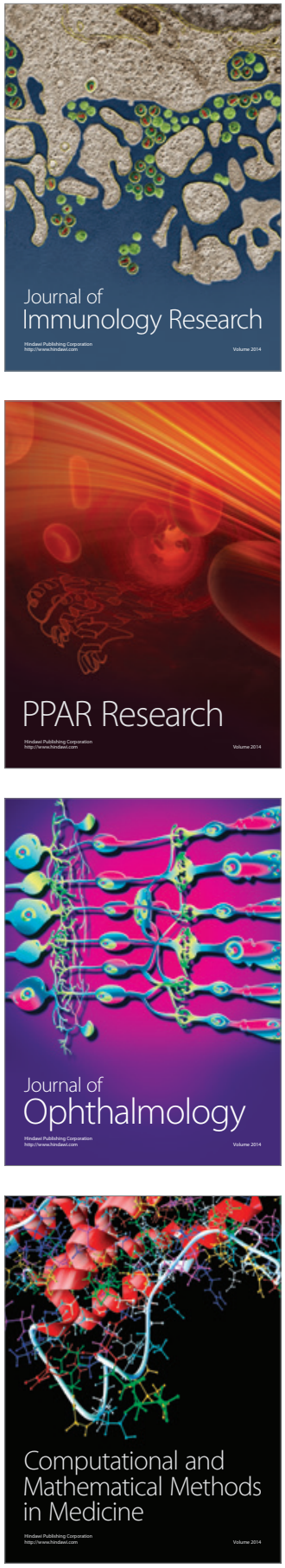

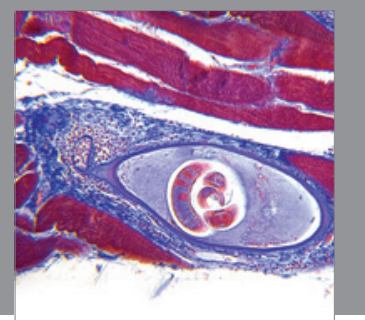

Gastroenterology

Research and Practice
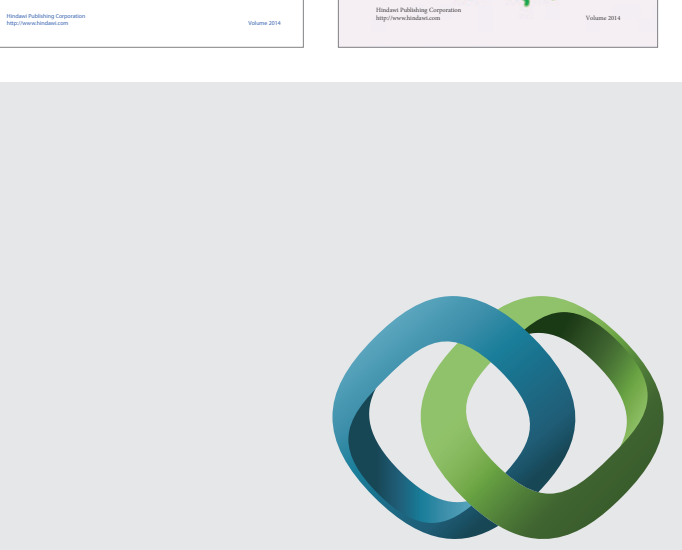

\section{Hindawi}

Submit your manuscripts at

http://www.hindawi.com
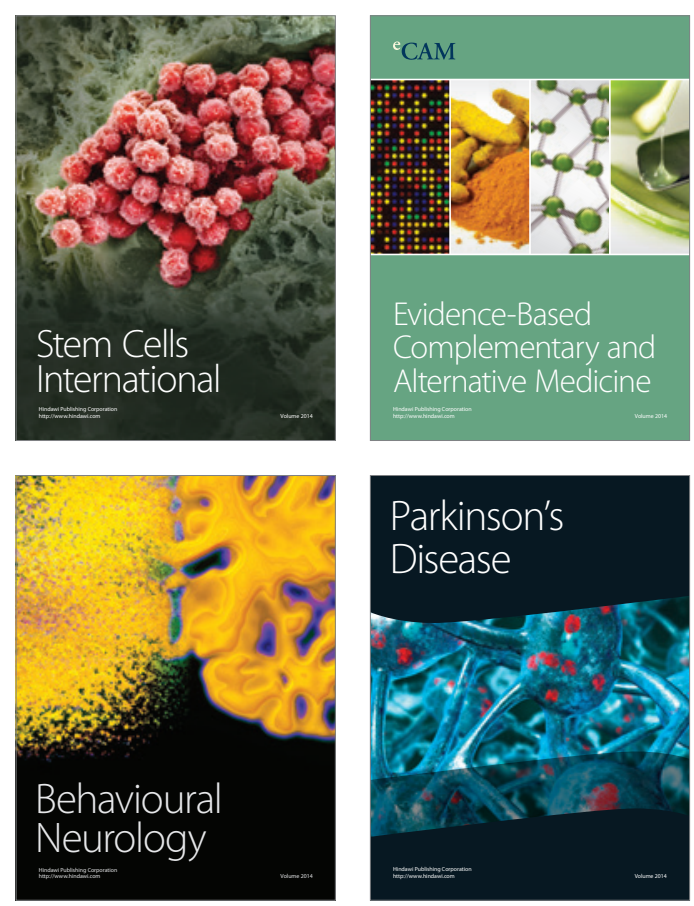

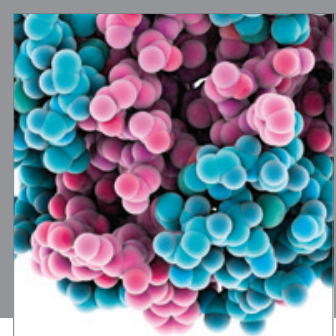

Journal of
Diabetes Research

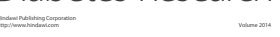

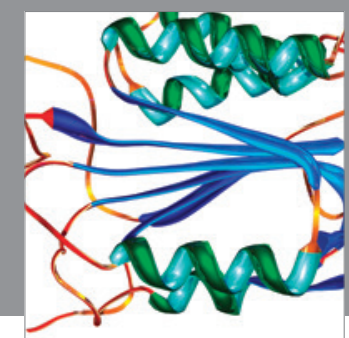

Disease Markers
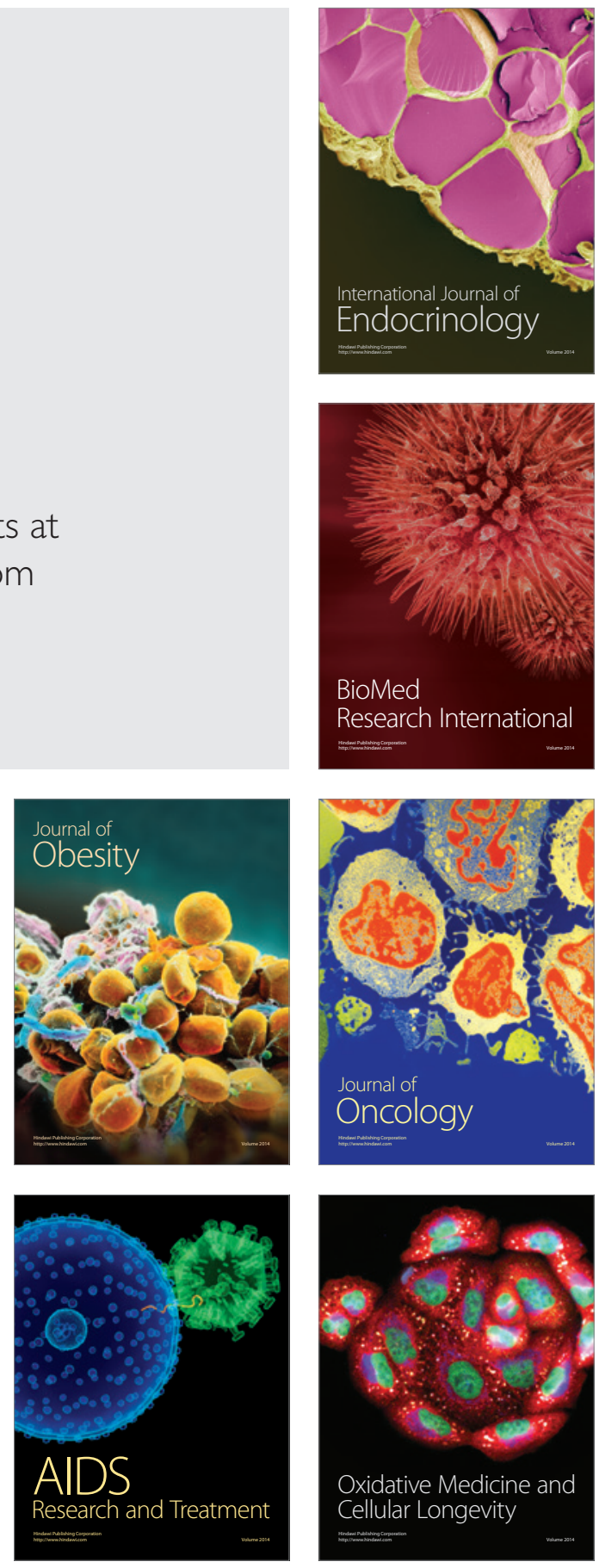